\title{
Cost-effectiveness of combination antiviral treatment with extended duration for hepatitis $B$ e antigen (HBeAg)-negative chronic hepatitis B in China
}

\author{
Runqin Li ${ }^{1 \#}$, Xiao Lin ${ }^{1 \#}$, Jing-Yue Wang ${ }^{2 \#}$, Xiaomo Wang ${ }^{3}$, Junfeng Lu ${ }^{1}$, Yali Liu ${ }^{4}$, Zhenhuan Cao ${ }^{1}$, \\ Shan Ren ${ }^{1}$, Lina $\mathrm{Ma}^{1}$, Yi Jin ${ }^{1}$, Sujun Zheng ${ }^{1}$, Zhongjie $\mathrm{Hu}^{1}$, Li Wang ${ }^{3}$, Xinyue Chen ${ }^{1}$ \\ ${ }^{1}$ The First Unit, Department of Hepatology, Beijing Youan Hospital, Capital Medical University, Beijing, China; ${ }^{2}$ Division of Hepatology, Beijing \\ Tsinghua Changgung Hospital, School of Clinical Medicine, Tsinghua University, Beijing, China; ${ }^{3}$ Department of Epidemiology and Biostatistics, \\ Institute of Basic Medical Sciences Chinese Academy of Medical Sciences, School of Basic Medicine Peking Union Medical College, Beijing, China; \\ ${ }^{4}$ The Third Unit, Department of Hepatology, Beijing Youan Hospital, Capital Medical University, Beijing, China \\ Contributions: (I) Conception and design: R Li, X Chen; (II) Administrative support: X Chen, L Wang, Z Hu, S Zheng; (III) Provision of study \\ materials or patients: R Li, X Lin, JY Wang; (IV) Collection and assembly of data: R Li, X Wang, J Lu, S Ren, L Ma, Y Jin; (V) Data analysis and \\ interpretation: R Li, L Wang, X Wang, Y Liu, Z Cao; (VI) Manuscript writing: All authors; (VII) Final approval of manuscript: All authors. \\ "These authors contributed equally to this work. \\ Correspondence to: Xinyue Chen, MS. The First Unit, Department of Hepatology, Beijing Youan Hospital, Capital Medical University, Beijing 100069, \\ China. Email: chenxydoc@ccmu.edu.cn; Li Wang, PhD. Department of Epidemiology and Biostatistics, Institute of Basic Medical Sciences Chinese \\ Academy of Medical Sciences, School of Basic Medicine Peking Union Medical College, Beijing 100005, China. Email: liwang@ibms.pumc.edu.cn.
}

Background: Hepatitis B surface antigen clearance or seroconversion is rarely achieved for patients using nucleoside analogs or pegylated interferon alpha monotherapy approaches. Several recent studies have confirmed the benefit of a combination of these two approaches for selected chronic hepatitis B patients. However, few reports have investigated long-term outcomes or health economic evaluation for hepatitis B surface antigen clearance. The aim of this study was to perform a cost-effectiveness analysis of the long-term use of this combination strategy among selected hepatitis B e antigen-negative patients.

Methods: Drawing on experience in China, we used a Markov model to simulate disease progression among a population of hepatitis B e antigen-negative chronic hepatitis B patients with surface antigen levels of $\leq 1,000 \mathrm{IU} / \mathrm{mL}$ through a discrete series of health states. We compared nucleoside analog monotherapy to the combination strategy over a prolonged period. We measured lifetime costs, quality-adjusted life-years and incremental cost-effectiveness ratios.

Results: The combination therapy produced 15.8 quality-adjusted life-years, and cost US dollars (USD) 45,032 per patient. The monotherapy gave 13.9 quality-adjusted life-years, and had a cost of USD 52,064. The incremental cost-effectiveness ratio of the monotherapy (USD -3,755 per quality-adjusted life-year) did not obtain extended dominance over combination therapy. The most cost-effective option was combination therapy among patients with hepatitis B surface antigen levels of $\leq 10 \mathrm{IU} / \mathrm{mL}$, which had the lowest calculated cost of USD 35,318 and most quality-adjusted life-years (16.7).

Conclusions: A long-term combination treatment strategy for selected hepatitis B e antigen-negative chronic hepatitis B patients may prolong quality-adjusted life-years compared with nucleoside analog monotherapy. Chronic hepatitis B patients with a hepatitis B surface antigen level of $\leq 10 \mathrm{IU} / \mathrm{mL}$ were the most cost-effective population under this strategy.

Keywords: Cost-effectiveness; chronic hepatitis B; hepatitis B surface antigen loss (HBsAg loss); functional cure; quality-adjusted life-years (QALYs)

Submitted Apr 05, 2021. Accepted for publication Jul 23, 2021.

doi: 10.21037/atm-21-1666

View this article at: https://dx.doi.org/10.21037/atm-21-1666 


\section{Introduction}

Hepatitis B virus (HBV) infection remains an important global public health problem with significant morbidity and mortality $(1,2)$. In China, approximately $5-6 \%$ of people are chronically infected with $\mathrm{HBV}$ and the risk of cirrhosis caused by hepatitis B is also increasing $(3,4)$.

According to the latest international and Chinese guidelines, sustained hepatitis B surface antigen (HBsAg) clearance or seroconversion is regarded as an optimal endpoint of antiviral treatment for patients with chronic hepatitis B. This is commonly termed a "functional cure" but is rarely achieved. The clearance rate is not more than $4 \%$ per year using current nucleoside analogs (NA) or pegylated interferon-alpha (Peg-IFN $\alpha)$ monotherapy approaches, and the 5 -year accumulative rate is $4-10 \%$ (5-7). The international guidelines recommend NA with long-term consolidation treatment until HBsAg loss, after HBV-DNA turns negative for patients with chronic hepatitis $\mathrm{B}$ e antigen ( $\mathrm{HBeAg}$ ) negative chronic hepatitis B. However, the proportion of HBsAg loss from long-term use of NAs is very low, and the risk of drug resistance, also makes the treatment limited for this group.

Several recent cohort studies, as well as clinical practice, have confirmed that a sequential or combination strategy of direct-acting antivirals such as NA or immunomodulators (e.g., Peg-IFN $\alpha$ ) may be effective in moving some selected patients with chronic hepatitis $\mathrm{B}$ towards a functional cure (8-12). A meta-analysis also showed that a longer period of Peg-IFN $\alpha$-based treatment of more than 48 weeks, was likely to improve the HBsAg clearance rate (13). Another multicenter trial showed that HBsAg seroclearance could be improved significantly from $2.8 \%$ to $9.1 \%$ by providing a combination of Peg-IFN and tenofovir rather than PegIFN alone (14). These findings support the use of a longterm combination treatment strategy. We explored the use of a NA and Peg-IFN $\alpha$ combination strategy for selected HBeAg-negative chronic hepatitis B patients, and observed a significant increase in HBsAg clearance rate of up to $28 \%$ under prolonged (up to 96 weeks) treatment (15). A further retrospective analysis found that $\mathrm{HBsAg}$ quantitation and decline at baseline and week 48 had a good predictive effect for HBsAg clearance rate at week 96. Patients with a low level of HBsAg at 48 weeks were the dominant population for HBsAg clearance. For these patients, it was more worthwhile to extend the course of NA combined with IFN treatment to pursue a functional cure (16). However, prolonging duration leads to much higher treatment cost, and there are few data to investigate the treatment cost and value for this strategy.

The purpose of this study was therefore to further evaluate the value of HBsAg clearance and carry out health economic analysis of a treatment strategy of a longterm combination of NA and Peg-IFNa for patients with HBeAg-negative chronic hepatitis B.

We present the following article in accordance with the Consolidated Health Economic Evaluation Reporting Standards (CHEERS) reporting checklist (available at https://dx.doi.org/10.21037/atm-21-1666).

\section{Methods}

The study was conducted in accordance with the Declaration of Helsinki (as revised in 2013). The study was approved by the Institutional Ethics Committee of the Beijing You'an Hospital, Capital Medical University, China $\{[2018] 050\}$.

\section{Strategies}

We aimed to explore the strategy of extended duration NA plus Peg-IFN $\alpha$ treatment for selected patients with HBeAgnegative chronic hepatitis, who had HBsAg $\leq 1,000 \mathrm{IU} / \mathrm{mL}$ and HBV-DNA $<100 \mathrm{IU} / \mathrm{mL}$. The population was treated with Peg-IFNa (135 or $180 \mu \mathrm{g} /$ week) combined with NA (Entecavir $0.5 \mathrm{mg}$ per day or Tenofovir disoproxil 300 mg per day). HBsAg clearance rate increased up to $28 \%$ under prolonged treatment of up to 96 weeks (15), and further retrospective analysis showed that HBsAg levels at week 48 could help to predict HBsAg clearance rate at week 96 (16). The HBsAg clearance rate differed after treatment in different groups. It was $6.7 \%$ among those with $100 \mathrm{IU} / \mathrm{mL}<\mathrm{HBsAg} \leq 1,000 \mathrm{IU} / \mathrm{mL}$, which was defined as the primary advantage population, $31.8 \%$ for those with $10 \mathrm{IU} / \mathrm{mL}<\mathrm{HBsAg} \leq 100 \mathrm{IU} / \mathrm{mL}$, or the middle advantage population, and $67.7 \%$ for those with $\mathrm{HBsAg} \leq 10 \mathrm{IU} / \mathrm{mL}$ who were defined as the super-advantage population (16).

On the basis of this strategy, we built a Markov model with HBsAg loss as a single outcome. We compared the effects and costs of combination therapy under the longterm combination of NA and Peg-IFN $\alpha$ with traditional NA monotherapy (Entecavir $0.5 \mathrm{mg}$ per day or Tenofovir disoproxil $300 \mathrm{mg}$ per day).

This health economic analysis provides further evidence on whether to pursue HBsAg loss in populations with different HBsAg levels at 48 weeks of treatment, and helps 




Figure 1 Diagram of the Markov model schematic with entry points of HBeAg-negative patients with chronic hepatitis B. CHB, chronic hepatitis B; CC, compensated cirrhosis; DCC, decompensated cirrhosis; HCC, hepatocellular carcinoma; LTP, liver transplantation; postLTP, post-liver transplantation; HBeAg, hepatitis B e antigen; HBsAg, hepatitis B surface antigen.

to define the population characteristics for achieving $\mathrm{HBsAg}$ clearance. It also matches the outcomes at the end of the lifecycle with clinical observations, to verify the clinical value of the Markov model.

\section{Markov model and cycle status}

We aimed to develop a Markov model to simulate the long-term disease progression and outcome for HBeAgnegative patients with chronic hepatitis $B$ who were 35 years old, using a treatment strategy of extendedduration combination NA and Peg-IFN $\alpha$.

The model does not apply to HBeAg-positive patients or drug-resistant patients. It included clinical endpoints for eight states among patients with $\mathrm{HBeAg}$-negative chronic hepatitis B: HBsAg clearance, compensated cirrhosis, decompensated cirrhosis, hepatocellular carcinoma, liver transplantation, post-liver transplantation and hepatitis B-related death. Patients from the initial state (having chronic hepatitis B) could move to other states with a defined transition probability, with death as the final state (see Figure 1). The life expectancy of Chinese people in Beijing was 82.2 years in 2018 (17), so 85 years old was set as the end of the cycle. The model's time horizon was 50 years, with a cycle length of 1 year, and patients from the initial state could either move to another state or remain in the same state after a 1-year cycle. A half-cycle correction was applied.

\section{Disease state transition probability}

The annual transition probability is the probability that a patient will move from one state to another within one cycle. The cumulative transition rate of different outcomes was examined for four groups of patients under NA monotherapy or combination Peg-IFN and NA treatment. They were as follows: (I) $\mathrm{HBsAg} \leq 1,000 \mathrm{IU} / \mathrm{mL}$ treated with NA; (II) HBsAg level of $100 \mathrm{IU} / \mathrm{mL}<\mathrm{HBsAg}$ $\leq 1,000 \mathrm{IU} / \mathrm{mL}$; (III) $10 \mathrm{IU} / \mathrm{mL}<\mathrm{HBsAg} \leq 100 \mathrm{IU} / \mathrm{mL}$ and (IV) $\mathrm{HBsAg} \leq 10 \mathrm{IU} / \mathrm{mL}$ treated with Peg-IFN $\alpha$ combined with NA followed by NA monotherapy after 96 weeks.

The HBsAg loss rate in the first 96 weeks in the model was based on our previous study data, and the transition rate between different disease states after 96 weeks was derived from the published literature and clinical practice data from Beijing. The calculated annual transition probability estimates are shown in Table 1.

The Markov model was calculated and implemented using TreeAge Pro 2011 (TreeAge Software, Williamstown, MA, USA). 
Table 1 Annual transition rates of disease states used in the Markov model

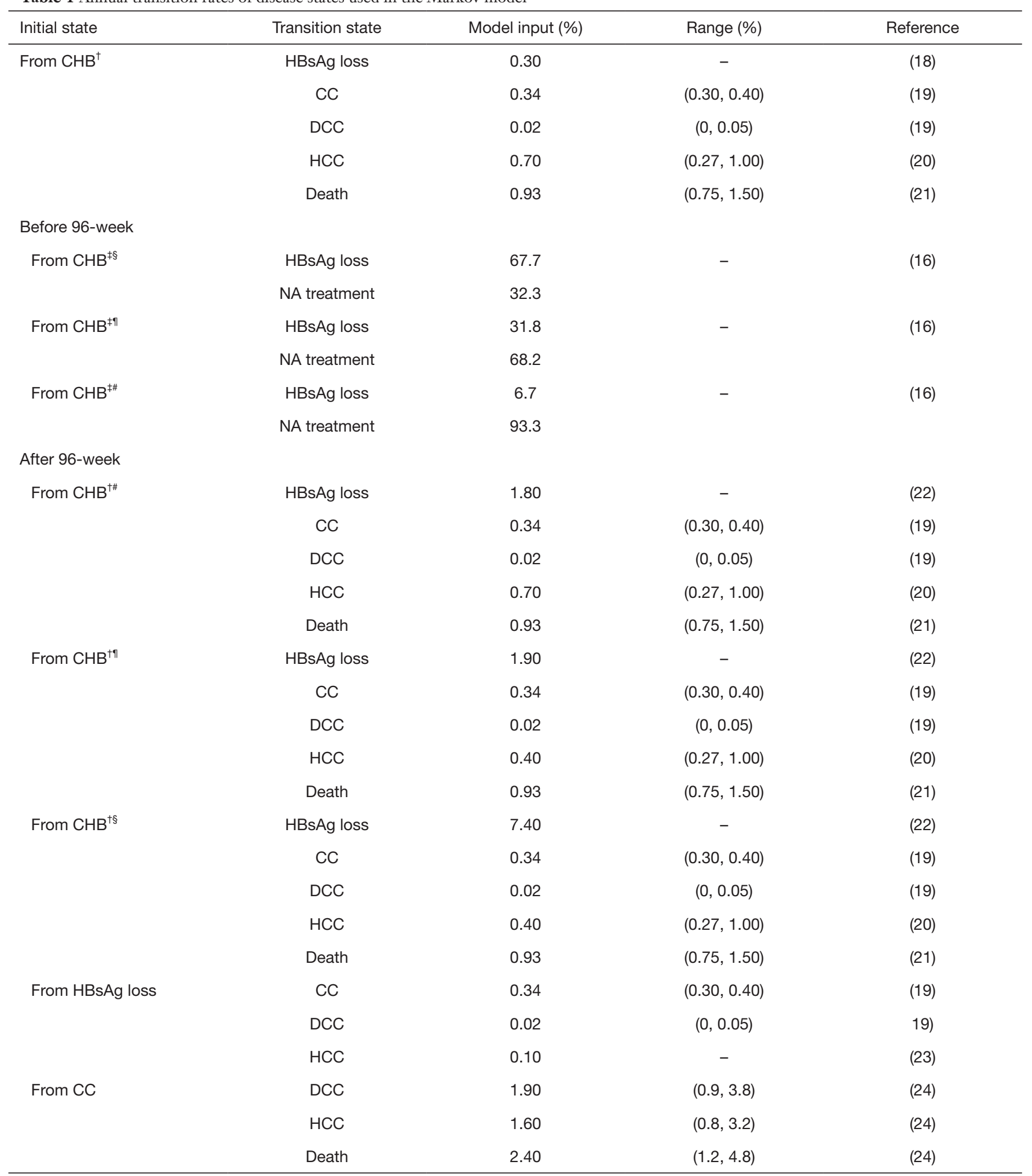

Table 1 (continued) 
Table 1 (continued)

\begin{tabular}{|c|c|c|c|c|}
\hline Initial state & Transition state & Model input (\%) & Range (\%) & Reference \\
\hline \multirow{2}{*}{ From DCC } & Liver transplantation & 5.50 & $(1.0,10.0)$ & $(25)$ \\
\hline & death & 15.00 & $(9.9,20.0)$ & $(20)$ \\
\hline Liver transplantation & Post-liver transplantation & 88.00 & $(89.2,86.8)$ & $(26)$ \\
\hline \multirow[t]{2}{*}{ Post-liver transplantation } & Death & 4.80 & $(4.3,5.3)$ & $(27)$ \\
\hline & HBV relapse & 8.10 & $(7.3,8.9)$ & $(27)$ \\
\hline \multirow[t]{2}{*}{ From HCC } & Liver transplantation & 5.50 & $(1.0,10.0)$ & (25) \\
\hline & Death & 54.50 & $(20.0,60.0)$ & $(20,28)$ \\
\hline
\end{tabular}

${ }^{\dagger}$, patients receiving NA monotherapy; ${ }^{\ddagger}$, patients receiving combination NA and Peg-IFN $\alpha$ therapy; ${ }^{\ddagger}$, population with $100 \mathrm{IU} / \mathrm{mL}<\mathrm{HBsAg}$ $\leq 1,000 \mathrm{IU} / \mathrm{mL}$ at 48 weeks treated with combination NA and Peg-IFN $\alpha$ before 96 weeks; ${ }^{\neq}$, population with $10 \mathrm{IU} / \mathrm{mL}<\mathrm{HBsAg} \leq 100 \mathrm{IU} / \mathrm{mL}$ at 48 weeks treated with combination NA and Peg-IFN $\alpha$ before 96 weeks; ${ }^{\ddagger}$, population with $\mathrm{HBsAg} \leq 10 \mathrm{IU} / \mathrm{mL}$ at $48 \mathrm{weeks}$ treated with combination NA and Peg-IFN $\alpha$ before 96 weeks; ${ }^{\dagger \#, ~ p o p u l a t i o n ~ w i t h ~} 100 \mathrm{IU} / \mathrm{mL}<\mathrm{HBsAg} \leq 1,000 \mathrm{IU} / \mathrm{mL}$ at 48 weeks treated with $\mathrm{NA}$ monotherapy after 96 weeks; ${ }^{\dagger \uparrow}$, population of $10 \mathrm{IU} / \mathrm{mL}<\mathrm{HBsAg} \leq 100 \mathrm{IU} / \mathrm{mL}$ at 48 weeks treated with NA monotherapy after $96 \mathrm{weeks}$; t\$, population of $\mathrm{HBsAg} \leq 10 \mathrm{IU} / \mathrm{mL}$ at 48 weeks treated with NA monotherapy after 96 weeks. Peg-IFN $\alpha$, pegylated interferon alpha; NA, nucleoside analogs; CHB, chronic hepatitis B; HBsAg, hepatitis B surface antigen; CC, compensated cirrhosis; DCC, decompensated cirrhosis; HCC, hepatocellular carcinoma.

\section{Cost-effectiveness and health economics evaluation}

\section{Health utility estimation}

From the perspectives of health care and patients, the medical cost of chronic hepatitis B patients, including both the costs of antiviral treatment and related medical care costs, were obtained from recent cost-effectiveness study analyses on Chinese people with chronic hepatitis B $(29,30)$, and used to estimate health state utility (Table 2).

\section{Cost and health economics evaluation}

The outcome measures were lifetime cost and qualityadjusted life-years (QALYs). Peg-IFN combined with NA was considered the reference therapy, and incremental cost-effectiveness ratios (ICERs) were used to determine the additional cost of each QALY when a treatment had a greater cost and effectiveness than the reference.

WHO CHOICE sets out that any treatment option with ICER less than GDP per capita can be considered extremely cost-effective. If ICER is more than one and less than three times GDP per capita, it is considered costeffective. If ICER is greater than or equal to three times GDP, the option is not cost-effective. In this study, we set the willingness to pay (WTP) threshold as three times the national GDP per capita in 2018. GDP per capita was around US dollars (USD) 9,750 (approximately RMB 64,521), so three times was USD 29,250 (RMB 193,562). All costs were converted to 2018 values in USDs using an exchange rate of $1 \mathrm{USD}=6.6174$ Chinese Yuan. The discount rate was determined to be $5 \%$ per annum (31).

Patients were treated using a long-term combination strategy, and costs included antiviral treatment costs, any necessary laboratory tests and any related patient management costs. We calculated the cost of anti-viral treatment based on the most recently published figures. We used medical management costs for chronic hepatitis B and other related costs from a retrospective pharmacoeconomic analysis in Beijing from February 2008 to December 2012 (32). All costs were inflated to 2018 prices using the China National Healthcare Index from the National Bureau of Statistics of China, and converted to USD using the official 2018 exchange rate $(1 \mathrm{USD}=6.2 \mathrm{RMB})$. The average annual drug cost and the costs of different disease states are shown in Table 3.

\section{Sensitivity analysis}

We used one-way and two-way sensitivity analysis and probabilistic sensitivity analysis to explore the impact of parameter uncertainty (33). First, we used Tornado Diagram 
Table 2 Mean utility estimates for chronic hepatitis B-related health states

\begin{tabular}{lcc}
\hline Health state utilities & Utility & Range \\
\hline HBsAg loss & 0.95 & $(0.90,0.99)$ \\
Chronic hepatitis B & 0.95 & $(0.90,0.99)$ \\
Compensated cirrhosis & 0.69 & $(0.66,0.71)$ \\
Decompensated cirrhosis & 0.35 & $(0.32,0.37)$ \\
Liver transplantation & 0.41 & $(0.37,0.45)$ \\
Post liver transplantation & 0.55 & $(0.49,0.61)$ \\
Hepatocellular carcinoma & 0.38 & $(0.36,0.41)$ \\
\hline
\end{tabular}

HBsAg, hepatitis B surface antigen.

Table 3 Average annual total drug cost and chronic hepatitis B-related patient management cost

\begin{tabular}{lcc}
\hline Treatment strategy \& cost & $\begin{array}{c}\text { Annual base- } \\
\text { case estimation } \\
\text { (Yuan, RMB) }\end{array}$ & $\begin{array}{c}\text { Annual base- } \\
\text { case estimation } \\
\text { (Dollar, USD) }\end{array}$ \\
\hline Treatment strategy & 6,700 & 1,012 \\
NA monotherapy & 48,000 & 7,254 \\
NA + Peg-IFN $\alpha$ & 1,978 & 299 \\
Disease-state cost ${ }^{\dagger}$ & 1,978 & 299 \\
HBsAg loss & 6,050 & 914 \\
Chronic hepatitis B & 42,519 & 6,425 \\
Cirrhosis & 86,384 & 13,054 \\
Decompensation cirrhosis & 448,878 & 67,833 \\
Hepatocellular carcinoma & 67,989 & 10,274 \\
\hline Liver transplantation (27) & & \\
\hline Post-liver transplantation (27) &
\end{tabular}

${ }^{\dagger}$, including the cost of annual medical management, laboratory testing and examinations. NA, nucleoside analogs; Peg-IFN $\alpha$, pegylated interferon alpha; HBsAg, hepatitis B surface antigen.

analysis to do a one-way sensitivity analysis. Parameters with impact ranking were screened out with the results expressed as tornado charts. Second, we used a probabilistic sensitivity analysis based on the Monte Carlo simulation method. Different types of parameters were given a specific distribution, and the simulation was performed 1,000 times to observe the stability of the model results. The results are shown as the cost-effectiveness acceptability curve, which indicates the probability that each alternative will become the most cost-effective treatment as a dominant strategy as the WTP changes. All parameters in the model had correspondingly appropriate distributions, $\beta$-distributions were assigned for probability and utility values, and cost variables were assumed to follow a gamma distribution.

\section{Results}

\section{Cost-effectiveness results and cumulative disease incidence}

The cumulative cost of NA monotherapy was USD 52,064 (RMB 344,526) and it gave 13.9 QALYs per patient. The combination therapy had a cost of USD 45,032 (RMB 297,998) and shared 15.8 QALYs. The ICER of NA monotherapy (USD -3,755/QALY) showed that NA monotherapy did not obtain extended dominance over combination therapy. The combination treatment of NA plus Peg-IFNa for selected HBeAg-negative patients therefore gave both more QALYs and lower costs under the Markov model estimation (Table 4). When ranking the cost of combination therapy groups, we found that the cost of the population with $\mathrm{HBsAg} \leq 10 \mathrm{IU} / \mathrm{mL}$ was the lowest, at USD 35,318 (RMB 233,714). The benefit was 16.7 QALYs, which was overall the best cost-effectiveness benefit.

Over their lifetime, we estimated that HBsAg loss would be achieved by $77 \%$ of the population with $\mathrm{HBsAg} \leq 10 \mathrm{IU} / \mathrm{mL}$, $52 \%$ of the group with $10 \mathrm{IU} / \mathrm{mL}<\mathrm{HBsAg} \leq 100 \mathrm{IU} / \mathrm{mL}$, and $38 \%$ of patients with $100 \mathrm{IU} / \mathrm{mL}<\mathrm{HBsAg} \leq 1,000 \mathrm{IU} / \mathrm{mL}$. However, if treated using NA monotherapy, only $8 \%$ of patients would achieve HBsAg loss.

\section{One-way and probabilistic sensitivity analysis}

The tornado graph for the top 10 most influential parameters (Figure 2) showed that the discount rate is the most significant factor. The results of the probabilistic sensitivity analysis relied on the changing WTP. Below the WTP threshold of USD 29,250 (RMB 193,562, three times the domestic GDP per capita in 2018) per QALY, the combination treatment became more cost-effective compared with NA monotherapy as WTP increased (see Figure 3). Additional two-way sensitivity analysis showed in Figure S1.

\section{Discussion}

\section{Treatment strategy using long-term combination NA and} Peg-IFNa

A "functional cure" is the optimal treatment endpoint 


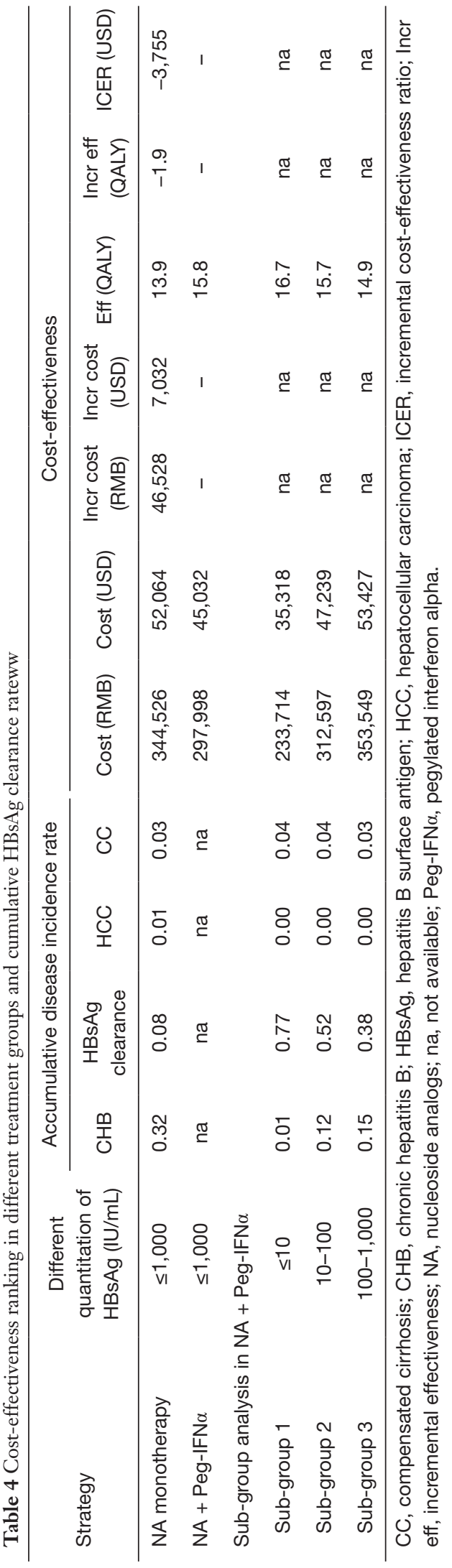

in the current domestic and international guidelines for chronic hepatitis B. The alternative options of a finite period of IFN, HBsAg loss or transition rate are still seldom used. Peg-IFNa and NA control hepatitis B using different mechanisms, so it is logical that combining the two may improve efficacy (34). Recent cohort studies used a combination of NA and IFN to improve the treatment efficacy by combination or longer treatment duration. Under the combination treatment strategy, we observed that HBsAg loss was significantly higher (28\%). Further retrospective analysis found that patients with low HBsAg at 48 weeks were the dominant population for a functional cure (12).

\section{Cost-effectiveness benefit}

"Value-based healthcare" requires a focus on health economics, and is especially important for innovative medicines emerging through recent and evolving drug development. The current epidemic has also encouraged health authorities, healthcare providers and patients to review value-oriented medication strategies. A systematic review by Wigfield et al. (35) analyzed 65 published articles of pharmacoeconomic evaluation, and only 11 of them mentioned treatment-related HBsAg loss or conversion. Most of the analyses did not evaluate functional cure. This may be because of the low possibility of HBsAg loss under traditional treatment options, making it impossible to carry out further analysis of cost-effectiveness. Along with treatment improvement, a functional cure is regarded as the gold standard of antiviral therapy. We therefore believe that it is essential to incorporate functional cure into pharmacoeconomic models. We targeted HBsAg clearance as a value evaluation point for hepatitis $B$ antiviral therapy to simulate anti-viral combination treatment strategies. Using the Markov model, we estimated the cumulative lifelong HBsAg loss rate was $76.5 \%$ for the population with HBsAg $\leq 10 \mathrm{IU} / \mathrm{mL}$ and $51.7 \%$ for the group with $10 \mathrm{IU} / \mathrm{mL}<\mathrm{HBsAg} \leq 100 \mathrm{IU} / \mathrm{mL}$ group, which was comparable to what we have observed in our clinical practice. That also demonstrated the practical value of this Markov model. Our new Markov model suggested that the cumulative cost with NA monotherapy was USD 52,064 with a gain of 13.9 QALYs. For patients receiving combined treatment, the cumulative cost was USD 45,032, and the cumulative effect 15.8 QALYs. Compared with NA monotherapy, the cost of the combination therapy was lower, but gave more QALYs. In the further sub-group 


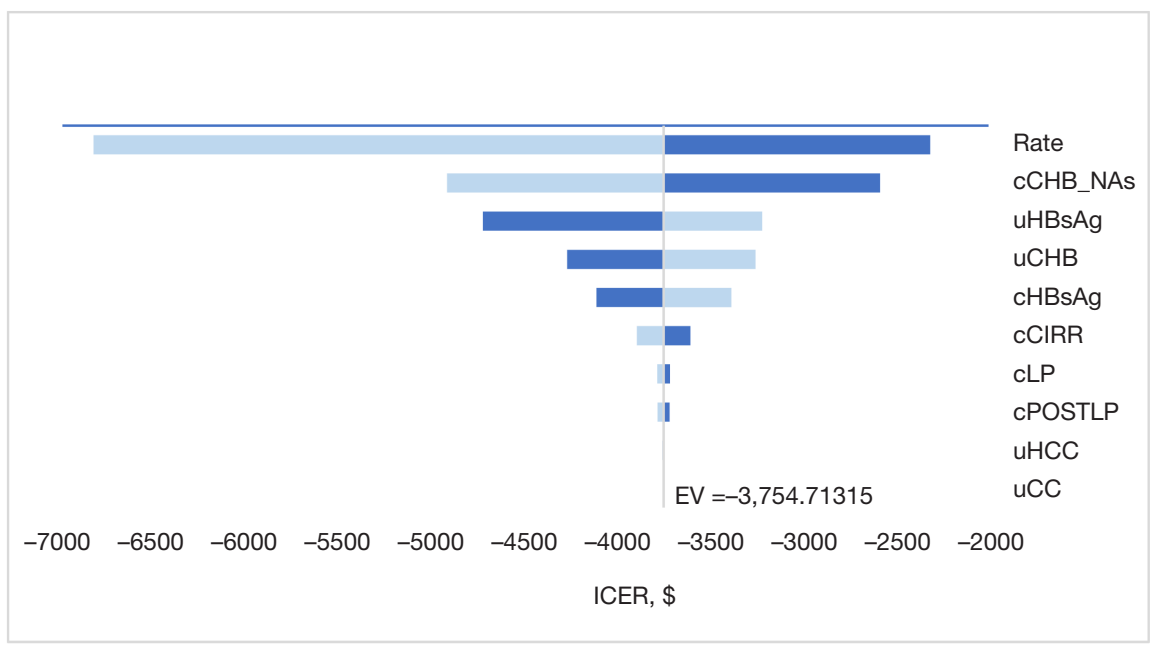

Figure 2 Results of one-way sensitivity analysis (Tornado analysis) at the threshold of willingness to pay (WTP) in China, which was USD 29,250 (RMB 193,562, three times the GDP per capita in 2018) per QALY. The dark blue portion of each bar represents the low range of the parameter on the y-axis, and the light blue portion the high range of the parameter. When dark blue is on the left and light blue on the right, the ICER increases as the parameter value increases; when light blue is on the left of the baseline, ICER decreases as parameter value increases. c, cost; CC, compensated cirrhosis; CHB, chronic hepatitis B; CIRR, cirrhosis; DCC, decompensated cirrhosis; EV, expected value; GDP, gross domestic product; HBsAg, hepatitis B surface antigen; HCC, hepatocellular carcinoma; ICER, incremental cost-effectiveness ratio; LP, liver transplantation; NA, nucleoside analogs; POSTLP, post-liver transplantation; QALY, quality-adjusted life-year; u, utility.



Figure 3 Cost-effectiveness acceptability curves of combination therapy for the base-case scenario. The y-axis shows the probability of cost-effectiveness. The $\mathrm{x}$-axis shows willingness to pay. NA, nucleoside analogs; Peg-IFNa, pegylated interferon alpha.

analysis, the population with $\mathrm{HBsAg} \leq 10 \mathrm{IU} / \mathrm{mL}$ had the lowest cumulative cost, USD 35,318, and the cumulative effect was 16.3 QALYs. This was also lower than the WTP threshold for the best cost-effectiveness option. In our real clinical observation, if patients treated with combination
NA and IFN see HBsAg loss within 96 weeks, the corresponding treatment cost will be lower than the Markov model simulation. The one-way sensitivity analysis showed that the discount rate has the greatest impact on the results. When the discount rate changed within the reference range and other parameters were kept at the baseline level, the population with $\mathrm{HBsAg} \leq 10 \mathrm{IU} / \mathrm{mL}$ receiving combination treatment was always the most cost-effective option. The same result was derived from the probability analysis. To our knowledge, this is the first analysis assessing the costeffectiveness of HBsAg loss on HBeAg-negative patients with chronic hepatitis B. This suggests that a treatment strategy using a long-term combination NA and PegIFN $\alpha$ could potentially enable a part of patients to obtain a much higher HBsAg loss rate with economic benefit as well. A published data by Chahal et al. on the use of monitoring and treatment for HBV high-risk groups can bring pharmacoeconomic benefits and reduce the burden of disease. Our research strategy has not been explored in high-risk groups (36). The benefits of combined intervention therapy on HBV high-risk populations need to be confirmed by additional data. 


\section{Limitations}

This study had some limitations. First, the Markov model did not include stability after HBsAg clearance or rescue treatment for recurrent cases. From a virological perspective, a functional cure is not the same as eradicating the HBV. The durability and recurrence after HBsAg loss are an essential way to evaluate the correlation with long-term treatment goals and improvement of clinical outcomes. Another prospective study from our research group demonstrated that the recurrence peak after HBsAg clearance or seroconversion was within 52 weeks (37). A recent meta-analysis review paper involving 43,924 patients with chronic hepatitis B found a total recurrence rate after HBsAg clearance of $6.19 \%$, with an average follow-up of 4.74 years. The overall stability was good (38), but there were significant differences between different research populations. We therefore did not include this data. Second, another limitation was the lack of large-sample prospective cohort follow-up data to supplement the long-term outcome evaluation after HBsAg loss in groups with different HBsAg titers. We used data retrieved from the literature, including review papers, as the reference. More data are needed to verify the long-term outcome after HBsAg clearance.

\section{Conclusions}

This pharmacoeconomic analysis showed that, using IFN combined with NA treatment gives more QALYs for patients with $\mathrm{HBsAg} \leq 1,000 \mathrm{IU} / \mathrm{mL}$, regardless of the HBsAg titer within that range. The population with the greatest advantage is that with $\mathrm{HBsAg} \leq 10 \mathrm{IU} / \mathrm{mL}$, where the cost-effectiveness is higher. The results of this study should enable HBeAg-negative populations to be treated more cost-effectively. Further prospective cohort studies would be needed to demonstrate the long-term clinical benefits.

\section{Acknowledgments}

Funding: This work was supported by National Science and Technology Key Project on "Major Infectious Diseases such as HIV/AIDS, Viral Hepatitis Prevention and Treatment" (2017ZX10202201, 2017ZX10302201-004), Capital Health Research and Development Projects (20201-2181), Qinghai Provincial Key Project of Research \& Development and Transformation (2017-SF-159).

\section{Footnote}

Reporting Checklist: The authors have completed the CHEERS reporting checklist. Available at https://dx.doi. org/10.21037/atm-21-1666

Data Sharing Statement: Available at https://dx.doi. org/10.21037/atm-21-1666

Peer Review File: Available at https://dx.doi.org/10.21037/ atm-21-1666

Conflicts of Interest: All authors have completed the ICMJE uniform disclosure form (available at https://dx.doi. org/10.21037/atm-21-1666). The authors have no conflicts of interest to declare.

Ethical Statement: The authors are accountable for all aspects of the work in ensuring that questions related to the accuracy or integrity of any part of the work are appropriately investigated and resolved. The study was conducted in accordance with the Declaration of Helsinki (as revised in 2013). The study was approved by the Institutional Ethics Committee of the Beijing You'an Hospital, Capital Medical University, China ([2018]050).

Open Access Statement: This is an Open Access article distributed in accordance with the Creative Commons Attribution-NonCommercial-NoDerivs 4.0 International License (CC BY-NC-ND 4.0), which permits the noncommercial replication and distribution of the article with the strict proviso that no changes or edits are made and the original work is properly cited (including links to both the formal publication through the relevant DOI and the license). See: https://creativecommons.org/licenses/by-nc-nd/4.0/.

\section{References}

1. Terrault NA, Lok ASF, McMahon BJ, et al. Update on prevention, diagnosis, and treatment of chronic hepatitis B: AASLD 2018 hepatitis B guidance. Hepatology 2018;67:1560-99.

2. Manne V, Gochanour E, Kowdley KV. Current perspectives into the evaluation and management of hepatitis B: a review. Hepatobiliary Surg Nutr 2019;8:361-9.

3. Zhang L, Fan ZF, Liu DW, et al. Trend analysis on the 


\section{Page 10 of 11}

disease burden related to cirrhosis and other chronic liver diseases caused by hepatitis B, in China, from 1990 to 2016. Zhonghua Liu Xing Bing Xue Za Zhi 2020;41:173-7.

4. Xie DY, Ren ZG, Zhou J, et al. 2019 Chinese clinical guidelines for the management of hepatocellular carcinoma: updates and insights. Hepatobiliary Surg Nutr 2020;9:452-63.

5. Chinese Society of Infectious Diseases, Chinese Medical Association; Chinese Society of Hepatology, Chinese Medical Association. The guidelines of prevention and treatment for chronic hepatitis B (2019 version). Chinese Journal of Hepatology 2019;27:938-61.

6. Sarin SK, Kumar M, Lau GK, et al. Asian-Pacific clinical practice guidelines on the management of hepatitis B: a 2015 update. Hepatol Int 2016;10:1-98.

7. Chinese Society of Infectious Diseases, Chinese Medical Association; Chinese Society of Hepatology, Chinese Medical Association. The expert consensus on clinical cure (functional cure) of chronic hepatitis B. Chinese Journal of Hepatology 2019;27:594-603.

8. Ning Q, Han M, Sun Y, et al. Switching from entecavir to PegIFN alfa-2a in patients with HBeAg-positive chronic hepatitis B: a randomised open-label trial (OSST trial). J Hepatol 2014;61:777-84.

9. Han $M$, Jiang J, Hou J, et al. Sustained immune control in HBeAg-positive patients who switched from entecavir therapy to pegylated interferon- $\alpha 2$ a: 1 year follow-up of the OSST study. Antivir Ther 2016;21:337-44.

10. Xie Q, Zhou H, Bai X, et al. A randomized, open-label clinical study of combined pegylated interferon Alfa2a (40KD) and entecavir treatment for hepatitis B "e" antigen-positive chronic hepatitis B. Clin Infect Dis 2014;59:1714-23.

11. Hu P, Shang J, Zhang W, et al. HBsAg Loss with Peginterferon Alfa-2a in Hepatitis B Patients with Partial Response to Nucleos(t)ide Analog: New Switch Study. J Clin Transl Hepatol 2018;6:25-34.

12. Lampertico $\mathrm{P}$, Brunetto $\mathrm{MR}$, Craxì A, et al. Add-on peginterferon alfa-2a to nucleos(t)ide analogue therapy for Caucasian patients with hepatitis B 'e' antigennegative chronic hepatitis B genotype D. J Viral Hepat 2019;26:118-25.

13. Ma Y, Wang J, Xiong F, et al. Extended duration therapy regimens based on Pegylated interferon for chronic hepatitis B patients focusing on hepatitis B surface antigen loss: A systematic review and meta-analysis. Infect Genet Evol 2020;85:104492.

\section{Li et al. Cost-effectiveness analysis on $\mathrm{HBeAg}$ negative $\mathrm{CHB}$ patients}

14. Cornberg M, Wong VW, Locarnini S, et al. The role of quantitative hepatitis B surface antigen revisited. J Hepatol 2017;66:398-411.

15. Cao ZH, Ma LN, Liu YL, et al. Efficacy and safety of peginterferon alfa-2a (40 kd) plus adefovir for 96 weeks in $\mathrm{HBeAg}$-negative chronic hepatitis B patients. Zhonghua Gan Zang Bing Za Zhi 2013;21:498-501.

16. Yan YJ, Wang XX, Cao ZH, et al. Low-levels of HBsAg quantification at 48-week in $\mathrm{HBeAg-negative} \mathrm{chronic}$ hepatitis B patients are the advantageous population for HBsAg clearance. Zhonghua Gan Zang Bing Za Zhi 2018;26:813-8.

17. Available online: http://wjw.beijing.gov.cn/xwzx_20031/ mtjj/201912/t20191227_1523552.html [Accessed Dec 25, 2019].

18. Lai CL, Shouval D, Lok AS, et al. Entecavir versus lamivudine for patients with $\mathrm{HBeAg}$-negative chronic hepatitis B. N Engl J Med 2006;354:1011-20.

19. Iloeje UH, Yang HI, Su J, et al. Predicting cirrhosis risk based on the level of circulating hepatitis B viral load. Gastroenterology 2006;130:678-86.

20. Lin X, Robinson NJ, Thursz M, et al. Chronic hepatitis $B$ virus infection in the Asia-Pacific region and Africa: review of disease progression. J Gastroenterol Hepatol 2005;20:833-43.

21. Xu B, Hu DC, Rosenberg DM, et al. Chronic hepatitis B: a long-term retrospective cohort study of disease progression in Shanghai, China. J Gastroenterol Hepatol 2003;18:1345-52.

22. Tseng TC, Liu CJ, Yang HC, et al. Determinants of spontaneous surface antigen loss in hepatitis B e antigennegative patients with a low viral load. Hepatology 2012;55:68-76.

23. Yip TC, Wong GL, Chan HL, et al. HBsAg seroclearance further reduces hepatocellular carcinoma risk after complete viral suppression with nucleos(t)ide analogues. J Hepatol 2019;70:361-70.

24. Fattovich G, Bortolotti F, Donato F. Natural history of chronic hepatitis B: special emphasis on disease progression and prognostic factors. J Hepatol 2008;48:335-52.

25. Wu B, Li T, Chen H, et al. Cost-effectiveness of nucleoside analog therapy for hepatitis B in China: a Markov analysis. Value Health 2010;13:592-600.

26. Lo CM, Fan ST, Liu CL, et al. The role and limitation of living donor liver transplantation for hepatocellular carcinoma. Liver Transpl 2004;10:440-7.

27. Wu TJ, Chan KM, Chou HS, et al. Liver transplantation in patients with hepatitis $\mathrm{B}$ virus-related hepatocellular 
carcinoma: the influence of viral characteristics on clinical outcome. Ann Surg Oncol 2013;20:3582-90.

28. Wang SB, Wang JH, Chen J, et al. Natural history of liver cirrhosis in south China based on a large cohort study in one center: a follow-up study for up to 5 years in 920 patients. Chin Med J (Engl) 2012;125:2157-62.

29. Toy M, Salomon JA, Jiang H, et al. Population health impact and cost-effectiveness of monitoring inactive chronic hepatitis B and treating eligible patients in Shanghai, China. Hepatology 2014;60:46-55.

30. Ke W, Zhang C, Liu L, et al. Cost-effectiveness analysis of tenofovir disoproxil fumarate for treatment of chronic hepatitis B in China. Hepatol Int 2016;10:924-36.

31. Haacker M, Hallett TB, Atun R. On discount rates for economic evaluations in global health. Health Policy Plan 2020;35:107-14.

32. Qiu Q. Effect of the partial reimbursement implementation of antivirals for Hepatitis B virus in Beijing: comparative effectiveness analysis and cost-effectiveness analysis based on a retrospecitve cohort study. Beijing: Chinese Academy of Medical Science \& Peking Union Medical College, 2015:1-183.

Cite this article as: Li R, Lin X, Wang JY, Wang X, Lu J, Liu Y, Cao Z, Ren S, Ma L, Jin Y, Zheng S, Hu Z, Wang L, Chen X. Cost-effectiveness of combination antiviral treatment with extended duration for hepatitis B e antigen (HBeAg)negative chronic hepatitis B in China. Ann Transl Med 2021;9(17):1365. doi: 10.21037/atm-21-1666
33. Lai K. Cost-effectiveness analysis of nucleos(t)ide analogue treatments for chronic hepatitis B patients. Guangdong, Guangdong Pharmaceutical University, 2017:1-88.

34. Wong GL, Wong VW, Chan HL. Combination therapy of interferon and nucleotide/nucleoside analogues for chronic hepatitis B. J Viral Hepat 2014;21:825-34.

35. Wigfield P, Sbarigia U, Hashim M, et al. Are Published Health Economic Models for Chronic Hepatitis B Appropriately Capturing the Benefits of HBsAg Loss? A Systematic Literature Review. Pharmacoecon Open 2020;4:403-18.

36. Chahal HS, Peters MG, Harris AM, et al. Costeffectiveness of Hepatitis B Virus Infection Screening and Treatment or Vaccination in 6 High-risk Populations in the United States. Open Forum Infect Dis 2019;6:ofy353.

37. Wu Y, Liu Y, Lu J, et al. Durability of Interferoninduced Hepatitis B Surface Antigen Seroclearance. Clin Gastroenterol Hepatol 2020;18:514-516.e2.

38. Song A, Wang X, Lu J, et al. Durability of hepatitis B surface antigen seroclearance and subsequent risk for hepatocellular carcinoma: A meta-analysis. J Viral Hepat 2021;28:601-12. 


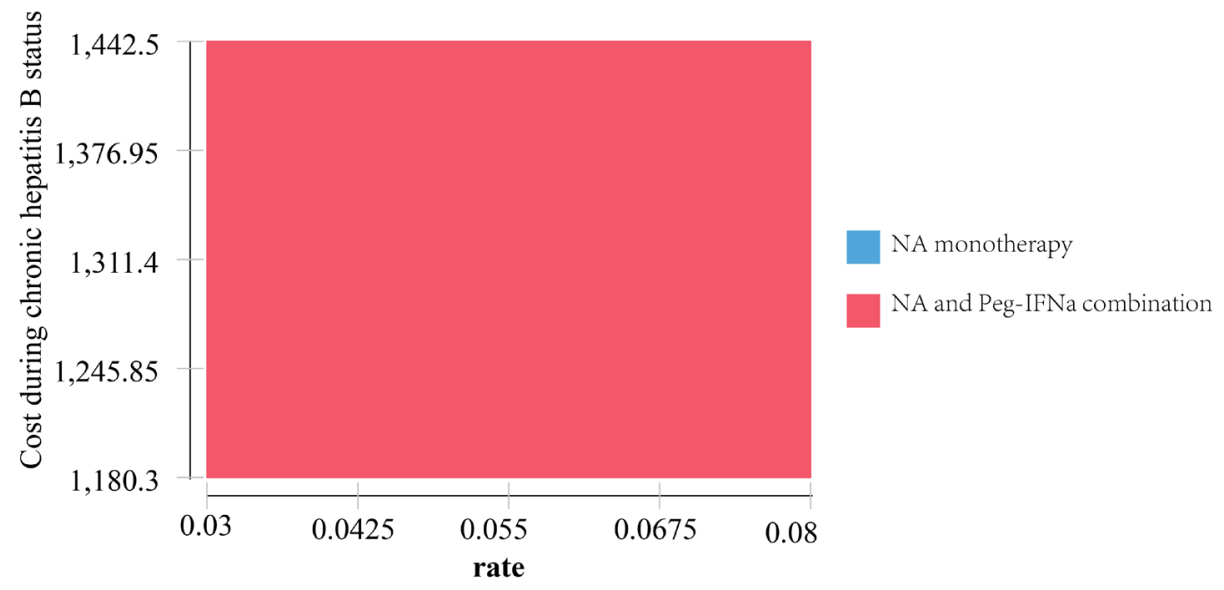

Figure S1 Two-way sensitivity analysis of the discount rate and the cost of CHB_NAs. Two-way sensitivity analyses based on two topranked parameters (discount rate and the cost of $\mathrm{CHB}$ status). The $\mathrm{x}$-axis indicates the different discount rates, while the $\mathrm{y}$-axis indicates the different costs of CHB. CHB, chronic hepatitis B; NA, nucleoside analogs; Peg-IFN $\alpha$, pegylated interferon alpha. 